\title{
A STUDY ON THE SKILLS OF MASTER OF ARTS IN RESEARCH PSYCHOLOGY GRADUATES FROM THE EMPLOYERS' PERSPECTIVE
}

\author{
A. W. R. Fynn* \\ Department of Institutional Research and Business Intelligence \\ e-mail: fynna@unisa.ac.za
}

\section{S. N. Dladla*}

Department of Psychology

e-mail: dladlasindi12@gmail.com

\section{H. Erasmus*}

Department of Psychology

e-mail: erasmhc@unisa.ac.za

*University of South Africa

Pretoria, South Africa

\section{ABSTRACT}

There is limited research into Research Psychology in general and even less research into employers' expectations of graduates from Research Psychology programmes. Calls from higher education institutions to improve graduate employability demonstrate the importance of exploring employer expectations. The method employed in this study was a cross-sectional design. Employers were surveyed to determine the types of industry in which graduates are employed, the institutions that employ the graduates and the skills required for their employment. Descriptive statistics and frequency counts were carried out to report the results. The study found that employers place much emphasis on the importance of soft skills, which is in contrast to the weight given to hard skills. In terms of research-specific skills, employers focus less on the academic research skills and more on the basic research skills that research programmes often take for granted. The matching of the organisation to the individual was considered important. Although this falls outside the offerings of research programmes, this match ensures the employment of the graduate and increases human capital development within organisations. The research problem was that while the existence of the skills gap between training outcomes and employer expectations is widely documented, relatively little research has been conducted into the expectations of employers of graduates within the field of Research Psychology. The study contributes to the understanding of the expectations of employers that affect employability outcomes and destinations of Research Psychology graduates.

Keywords: employability, higher education institutions, Master of Arts in Research Psychology, employability skills 


\section{INTRODUCTION}

Employability is often discussed while considering basic and transferable skills and context-dependent and context-independent skills (Griesel and Parker 2009). Employability is wider than the simple conceptualisation of key skills and includes a mix of personal qualities, beliefs, understandings, attributes and the ability to reflect on practice (Griesel and Parker 2009; Knight and Yorke 2003; Yorke 2005). The focus of this article is the employability of Master of Arts (MA) Research Psychology graduates based on employer expectations.

Increasing attention is being placed on employability by higher education institutions (HEIs). Higher education institutions are expected to engage proactively with the skill needs of the economy and to address the social imperatives that drive South Africa's development (Griesel and Parker 2009). However, employers continue to express concern about the gaps between the outcomes of higher education such as the quality, type and quantity of graduates and the needs of the economy (Yorke 2006). Higher education institutions are expected to take proactive steps to align their training outcomes with the needs and expectations of employers in order to improve graduate employability.

Research Psychology is a specialist category of psychology. It is offered at eight HEIs across South Africa. Research Psychology is one of the lesser-known categories of psychology, and concerns have been raised about the role and place of the discipline within the employment market (Rascher 2016). Existing research on the employability of Research Psychology graduates focuses on graduate destinations, and only limited research has been done into the expectations of the employers of the graduates from these programmes. The purpose of this article is to identify the employability skills that employers expect MA Research Psychology graduates to possess when they enter their organisations. This article highlights whether or not HEIs who offer MA Research Psychology programmes are producing desired graduates with the necessary skills to gain employment within the industry. The objective is to determine who employs the MA Research Psychology graduates and to assist the programmes in aligning their training outcomes with the needs of the employers.

\section{Employability}

Coetzee and Schreuder (2011) argue that employability is a psychosocial construct that represents career-related attributes. The position taken by Yorke (2006) to define employability highlights the mix of skills, knowledge and individual attributes that employers consider desirable and appraise when establishing which individuals are deemed employable. Cai (2013) elaborates on the definition of Yorke (2006) by pointing out that employers draw their beliefs 
about employable graduates from their experiences, the larger norms within their industry and the regulations that govern their industry. Employability, therefore, cannot be simply understood as inherent in individual graduates as defined by Coetzee and Schreuder (2011) or as the outcome of the teaching and learning at institutions or as the expectations and beliefs held by employers. Rather, by using the definitions offered by Yorke (2006) and Cai (2013), employability emerges as a complex and dynamic interaction between the graduate, the HEI and the employer. This interaction creates a meaning-making process in defining employability and requires reflexive engagement on the part of HEIs in their attempt to align notions of graduateness with notions of employability.

The concept of graduateness is understood as the attributes that graduates acquire during the course of their university studies. One of the difficulties in developing a universal definition of graduateness is the overlap with the concept of employability (Archer and Chetty 2013). Therefore, definitions of both terms vary depending on the context and theoretical orientation of scholars, with some scholars using the terms interchangeably. With reference to the current study, Bowden, Hart, King, Trigwell and Watts, as cited in Bridgstock (2009) define graduate attributes as

"[T]he qualities, skills and understandings a university community agree its students would desirably develop during their time at the institution, consequently shape the contribution they are able to make to their profession and as a citizen." $(2009,32)$

This definition of graduateness relates directly to the concept of employability and draws attention to the attributes that an individual needs in order to seek and to maintain employment. Graduateness encompasses the graduate's skills, knowledge and understanding and employability is concerned with the capacity of the graduate to enter and function in a job (Archer and Chetty 2013). Graduateness and employability intersect when graduates gain the qualities and skills from HEIs that are needed to transfer them into employment and to "hit the ground running" (Kruss 2004, 682).

In 2009 the Higher Education South Africa (HESA) and the South African Qualifications Authority (SAQA) conducted a baseline study on South African graduates from the perspective of the employers. Based on the findings, the authors Griesel and Parker (2009) it was argued that employers need to be realistic about the extent to which higher education can address the gap between higher education outcomes and employer expectations. According to Archer and Chetty (2013), it was also argued that employers need to consider their role in providing onthe-job training and ensuring the continuous development of graduates. Such studies demonstrate employability as a performance function of universities and thus, universities must 
be responsive to the developmental and economic challenges confronting South Africa (Clapper 2012).

Completion of a degree or diploma represents the end of formal education and training, and the assumption is that graduates will immediately proceed to the workplace (Kruss 2004). Employers expect graduates to have developed a range of skills, understandings and qualities appropriate for employment and need to be convinced that graduates will demonstrate employment-related skills (Cheong et al. 2016; Collet, Hine and Du Plessis 2015). The abovementioned baseline study referenced by Archer and Chetty (2013) shows evidence of a gap between what the universities intend to produce, the actual capabilities of the students and the employers' perceptions of key employability skills.

In response to this gap, Kruss (2004) from the Human Science Research Council (HSRC) conducted a study to assess the higher education responsiveness that is expected by key employers in the public and private sectors. Kruss (2004) findings suggested that the expectations of the public sector regarding higher education responsiveness were framed around a discourse characterised by a strong commitment to the national economy and social development with the emphasis on equity to redress the inequalities of the past (Kruss 2004). Employers in both the public and private sectors expressed that there is a relationship between higher education and the labour market, but there seems to be a gap between what the industry needs from graduates and the type of graduates that are produced (Kruss 2004). Stasz (2001) argues that the gap between the supply and the demand for skills requires a change in the education and training system and calls for adjustments to the school curriculum to increase employability. Changes in the nature of society and work in South Africa and the rest of the world require institutions to rethink their curricular and instructional practices (Council of Higher Education 2011).

While employability as a concept subsumes debates regarding desirable and marketable skills, it remains necessary to discuss the concept of skills within the broader concept of employability. The debates on skills within the concept of employability revolve around discipline or industry-specific skills in addition to generic or transferable skills. Stasz (2001, 386) identifies four broad skill areas:

- Academic/cognitive skills: These skills are associated with the subject area; knowledge about these subjects is primarily learnt in school and the skills are expected to be transferable outside the classroom setting.

- Generic skills/transferable skills: These skills are thought to be broadly transferable across work settings although they can assume a different meaning in different work contexts. 
- Technical skills/hard skills: These skills refer to the specific skills needed within a work placement but may also refer to academic skills. The individual needs to have specific knowledge of certain tools or processes.

- Work related attitudes/soft skills: These skills are the most difficult to define and conceptualise and can refer to an individual's character or personality shown within the workplace. These skills can denote traits such as personal motivation.

A postgraduate qualification is an indication that a certain level or area of specialisation has been reached (Moleke 2003). Individuals with postgraduate qualifications have better employment prospects and are able to use the best of their skills. Programmes regarding MA Research Psychology focus on the methodological approaches towards psychological research. Certain skill sets are required to execute research within the Social Sciences. The National Council for the Social Sciences (n.d.) in the United States asserts that skills in social studies enable students to apply knowledge proficiently in a variety of contexts and to develop the ability to address societal conflict and problems.

In terms of social skills, the National Council for the Social Studies (n.d.) outlined five skills that curriculum programmes should cover: literacy skills; critical thinking skills; research-based literacy strategies; learning strategies and personal interaction; and civic engagement strategies. The School of the Humanities and Social Sciences at the University of Cambridge has outlined the core skill areas that research students are expected to have developed throughout their studies; self-awareness; organisational skills; communication skills; networking and team-working skills; and career management. The university has categorised these skills as transferable skills that are developed specifically in students who are conducting postgraduate research. These skills are transferable in a sense that even if students do not choose academia as a career path, the skills are still useful in areas of industry outside research. Skills cannot be separated from the person; skills build capital that the individual can use to enhance employability attributes.

\section{Research psychology}

Psychology has become an increasingly popular course taught within Humanities at South African universities. All 26 universities in the country offer psychology courses at both undergraduate and postgraduate levels (Rascher 2016). Of the 26 universities that offer psychology courses, the Board of Psychology of the Health Professionals Council of South Africa (HPCSA) accredits 23 (HPCSA 2017). However, Van der Westhuizen (2000) and Plug (1990) and Louw (1992) (as cited in Derman 2002) agree that at postgraduate level, particularly 
master's, Research Psychology is a relatively underrepresented discipline.

Derman (2002) quotes the definition of Research Psychology according to the South African Department of Labour:

"[T]he study of methods used to investigate psychological and societal issues in order to generate psychological and social theories for the purpose of understanding and dealing effectively with these issues." (Derman 2002, 3)

Similar to the concept of employability, there is no shared definition of Research Psychology. Derman (2002) states that studied definitions of Research Psychology may differ vastly depending on the epistemological perspective, paradigm and time.

The purpose of Research Psychology within the field of South African psychology is to develop psychological interventions, psychological assessment and theories that are relevant to South African context and culturally sensitive to the diversity of South Africa (Long and Fynn 2018). Research psychology's categorisation as a professional category of practice within South African psychology means that it is influenced and regulated by the Health Professionals Council of South Africa (HPCSA). The role of Research Psychology as a profession in South Africa ensures that access to psychological knowledge and psychological practice is disseminated amongst the broader population of South Africa (Long and Fynn 2018).

Typically, the course content of an MA Research Psychology programme would include the philosophical foundations of research; research methods (qualitative and quantitative techniques, experimental methods); data collection techniques (participant observation, interviews, survey design); research proposal writing; and project management (Derman 2002; Rascher 2016). These skills are the basic skills of research that can be transferred to any context or sector that requires a research component.

As cited in Rascher (2016), Bedell and Phanyane (1998) identified a number of sectors, both public and private, that Research Psychology graduates could occupy such as government, the marketing industry, human resources, non-governmental organisations and tertiary education institutions. Laher (2005) describes Research Psychologists as engaging in activities such as developing new theories, evaluating existing psychological theories, supporting practitioners, enhancing quality of research output and the supervision and training of other Research Psychologists. State and federal governments, the military and large corporations and businesses (Rascher 2016) employ very few research psychologists compared with the number of psychologists employed as either academics or full-time researchers in universities and colleges. Over time, the competencies of researchers appear similar, irrespective of the context in which the competencies are applied. These contexts may range from, for example, a 
laboratory in an urban centre to a rural community in the Eastern Cape (Derman 2002).

Bedell and Phayane (1998) (as cited in Rascher 2016 and Derman 2002) report in their study that employers do not specifically look for research psychologists but rather seek people who possess the skills that are introduced during the course of the degree. This indicates that while having a master's degree in Research Psychology is potentially valuable in the workplace, the title of "Research Psychologist" is not necessarily required if one has the same skills (Rascher 2016).

\section{The Unisa Research Psychology Master's Programme}

The Unisa Master's in Research Consultation (MARC) is one of the six Research Psychology programmes that lead to registration with the HPCSA. The programme duration is four years, with the first year dedicated to an on-campus, structured coursework programme and three years' distance education during which students are required to complete their dissertation. The on-campus year focuses on developing students' theoretical knowledge and applied skills, while exposure to the workplace is provided through two placement periods of ten weeks each. The on-campus year is a structured programme during which various workshops relating to psychological research are presented to the MARC students throughout the year. Although this structure allows for unique characteristics, students undertaking this degree are required to be available for full-time, on-campus classes during their first MARC year. In some cases, this requires students to relocate (Fourie, Fynn and Long 2014).

The first year of the MARC covers core focus areas (Figure 1). The MARC programme places a strong emphasis on active learning through authentic learning experiences and consequently makes extensive use of work-integrated learning in the training model. Approximately 30 per cent of the first year of the MARC is dedicated to preparation, participation and reflection on practical placements where students are placed with organisations of their choice to participate actively in research environments. Furthermore, the MARC programme aims to provide students with sufficient exposure to both quantitative and qualitative methods. Therefore, approximately 10 per cent of the MARC first year is spent on quantitative research approaches and approximately 15 per cent of the time is spent on qualitative research approaches.

The dissertation proposal is the core assessment outcome of the MARC first year, and successful completion of the first year is signalled by an approved proposal. As such, the proposal development process plays a strong role in the development of students during the course of the year, with approximately 8 per cent of the time dedicated to the process. The programme also places emphasis on developing students' consultation knowledge and abilities 
through a series of workshops in which they are exposed to budgeting, contracting, customer management, marketing and brand-identity development.

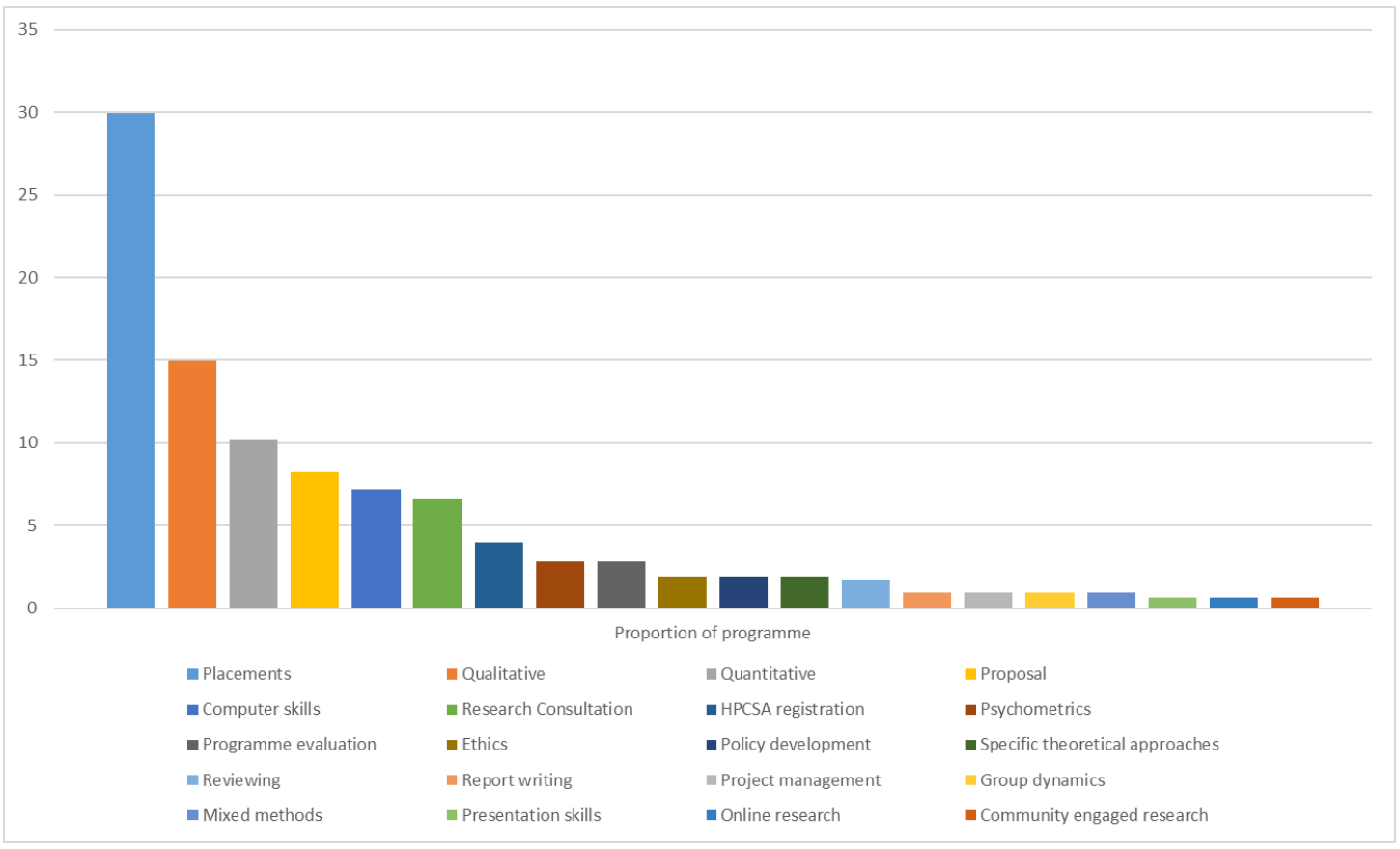

Figure 1: Curriculum structure of the MARC on-campus programme

Computer skills are viewed as one of the fundamental skills required among employable graduates and currently the MARC programme dedicates approximately 7 per cent of the on-campus year to the development of basic computer skills such as web searches and the use of MS Office packages and specialist software such as ATLAS.ti and SPSS. Students are also exposed to areas such as policy development, project management, group facilitation processes, presentation skills, report writing, psychometric instrument development, online research techniques and research ethics.

In addition, students are guided through the required processes and procedures to register with the HPCSA through a series of workshops and seminars aimed at creating awareness of the HPCSA requirements for registration as a psychologist.

\section{METHODOLOGY}

Ethical clearance and research permission was obtained from the University of South Africa (Unisa). The study employed a descriptive, cross-sectional design and snowball sampling because relatively little research into employer expectations of Research Psychology graduates exists and as such, a database or network of contacts from which employers could be identified was not readily available. The survey was developed on the Qualtrics ${ }^{\mathrm{XM}}$ survey platform and distributed via email using an anonymous survey link that collected non-identifiable information from the respondents. The survey included an informed consent page that needed 
to be accepted before continuing with the survey. The University of the Witwatersrand (WITS), Unisa, the University of KwaZulu-Natal (UKZN), North-West University (NWU), the University of Pretoria (UP) and the University of the Western Cape (UWC) provide HPCSA-accredited MA Research Psychology programmes (Health Professions Council of South Africa 2017). The course coordinators of these programmes were requested to forward the survey to their work placement networks or to any known organisations that hire their graduates. In addition, the researchers approached the Psychological Society of South Africa (PsySSA), Division for Research Methods, to distribute the survey through their online communication channels and their social networks. The desired respondents were employers who work directly with Research Psychology graduates within their organisation.

This study adapted the Unisa employer survey that was conceptualised by the College of Accounting Sciences and the College of Economic and Management Sciences (CEMS). The survey was administered to employers who hired graduates and included employer profiles that comprised data on geographical location, type of industry and position within the organisation. The survey also included a ranking question. Employers are asked to rank institutions that offer accredited training programmes in order to determine whether or not the institutions at which the graduates trained influenced their employability.

Likert scales were used to rate the items listed in the different skill domains. Each item had a rating scale ranging from "Not at all important", "Slightly Important", "Moderately Important", "Very Important" and "N/A". The skill domains covered in the survey were basic skills and understanding, applied knowledge, workplace skills, and interactive and personal skills.

The skill domains used in the survey covered general and specific skills. The specific skills identified skills that were deemed by employers as important for graduates to possess within their organisation. The generic skills identified the employable skills that graduates must have to enter and be successful in the workplace.

The final data set was cleaned, recoded and analysed using the Microsoft (MS) Excel software. Since the study was descriptive in nature, the analysis included descriptive statistics to describe the sample, and frequency counts were conducted to indicate which skills and attributes were in high demand among employers.

\section{RESULTS}

\section{Rankings}

This section presents the respondents' rankings of institutions according to their preferences when employing graduates. Using a drag-and-drop option, the respondents ranked the 
institutions from most preferred $(1=$ highest ranking) to least preferred $(7=$ lowest ranking). Therefore, the data was reversed scored and weighted in order to obtain a depiction of which institutions respondents preferred when employing graduates.

Table 1: University rankings

\begin{tabular}{|l|c|c|}
\hline & Total *weighted scores & Rank \\
\hline UNISA & 76 & 1 \\
\hline UWC & 63 & 3 \\
\hline WITS & 66 & 2 \\
\hline UKZN & 51 & 4 \\
\hline NWU & 50 & 5 \\
\hline UP & 43 & 6 \\
\hline
\end{tabular}

The most preferred institution was Unisa, followed by WITS and UWC. The institutions UKZN, NWU and UP were ranked lower (Table 1).

Table 2: Reasons for the top ranking

\begin{tabular}{|l|c|}
\hline Reputable institution & $33 \%$ \\
\hline Accredited course material & $13 \%$ \\
\hline Credible assessment system & $8 \%$ \\
\hline History and experience in higher education & $13 \%$ \\
\hline Competent graduates & $23 \%$ \\
\hline Only graduates from that institution apply & $5 \%$ \\
\hline Other: Please specify & $5 \%$ \\
\hline N/A & $0 \%$ \\
\hline
\end{tabular}

The reasons for the high ranking of institutions included the reputation of the institution $(n=13)$, the competence of the graduates $(n=9)$, the institution's history and experience in higher education $(n=5)$ and the use of accredited course material $(n=5)$ (Table 2).

Table 3: Reasons for the lowest ranking

\begin{tabular}{|l|c|}
\hline Poor reputation of the institution & $26 \%$ \\
\hline Quality of qualifications is questionable & $13 \%$ \\
\hline Quality of the assessment system is questionable & $8 \%$ \\
\hline Incompetent graduates & $13 \%$ \\
\hline Perceived as not being a credible institution & $21 \%$ \\
\hline Other: Please specify & $10 \%$ \\
\hline N/A & $10 \%$ \\
\hline
\end{tabular}

The three main reasons for the low ranking of institutions were poor reputation of the institution 
$(n=10)$, perceived as not being a credible institution $(n=8)$, incompetent graduates $(n=5)$ and questionable quality of the qualification $(n=5)$ (Table 3$)$.

Regarding their preference of institution when employing graduates, employers deem the reputation of the institution as important $(n=10)$. The reputation of the institution seems to be closely related to perceived as not being a credible institution $(n=8)$.

\section{Ratings of skill domains}

The results reported below are based on the responses of the 12 respondents who completed the full survey. In addition to institutional rankings, employers were asked to rate specific hard and soft skill domains and to indicate the graduate attributes that they value in their organisations. The set of attributes displayed in Figure 2 represents the career-related attributes that the graduate needs to possess in order to seek and maintain employment (Potgieter and Coetzee 2013).

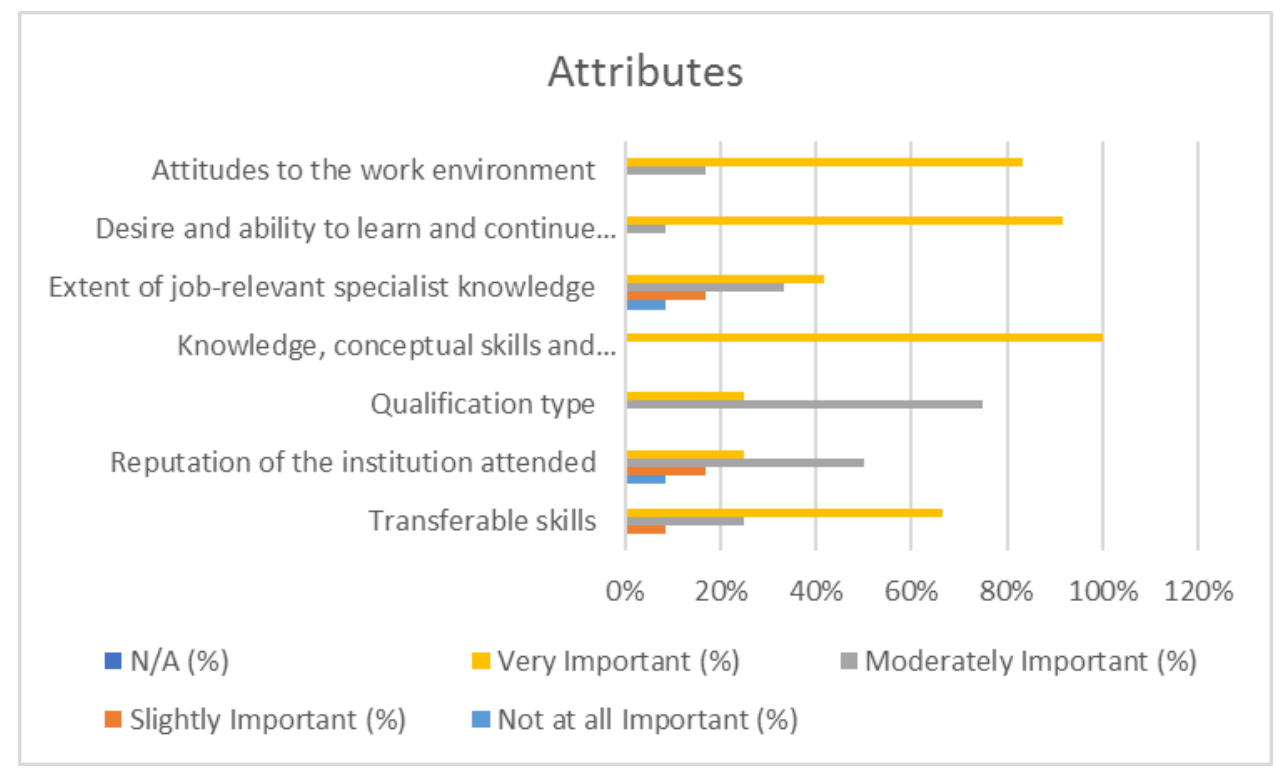

Figure 2: Attributes

All the respondents deemed knowledge, conceptual skills and understanding as extremely important $(n=12 ; 100 \%)$. Other attributes deemed important included the desire and ability to learn $(n=11 ; 92 \%)$, attitudes to the work environment $(n=10 ; 83 \%)$ and transferable skills $(n=8$; $67 \%)$. Qualification type $(n=9 ; 75 \%)$ and the reputation of the institution attended $(n=6 ; 50 \%)$ were considered as moderately important (Figure 3). 


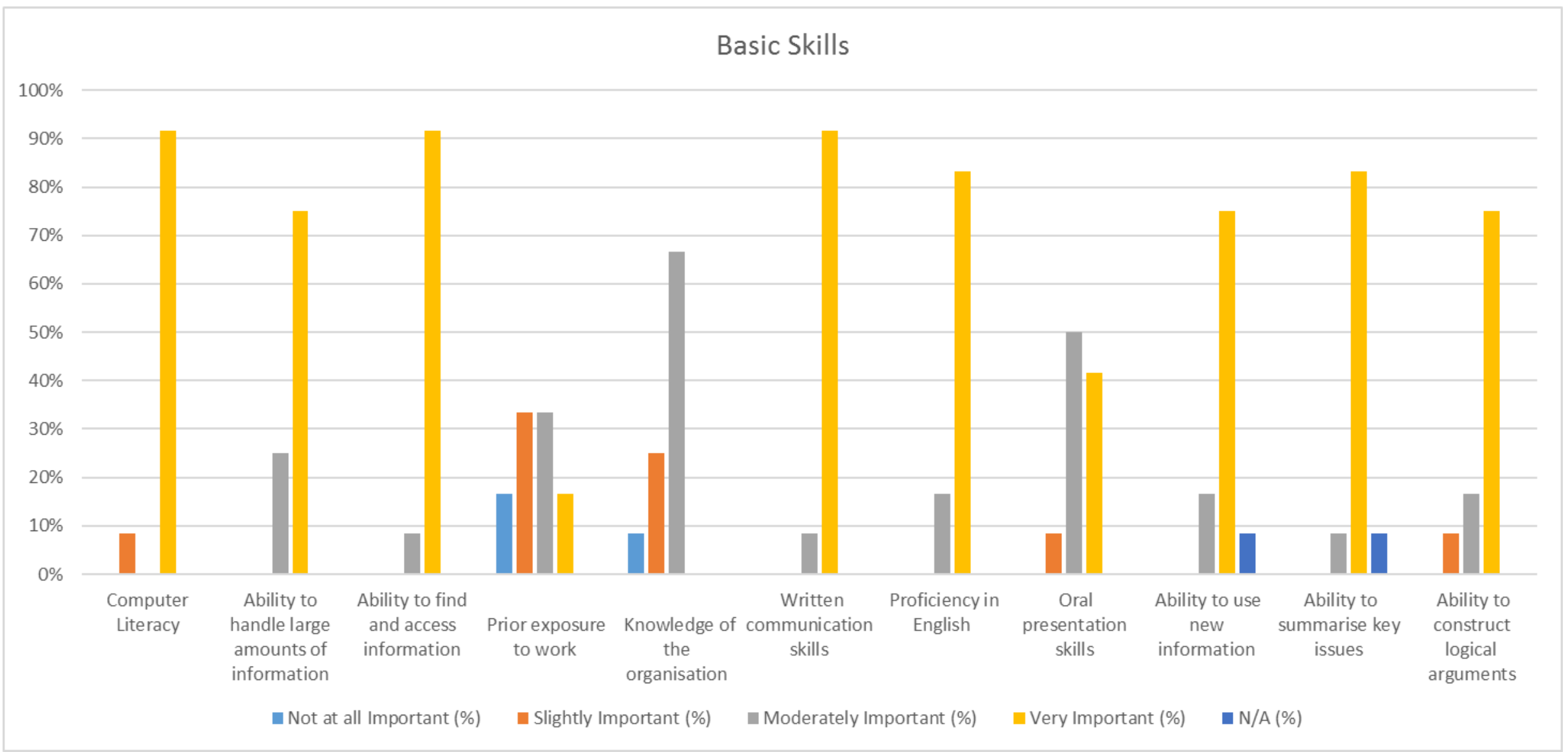

Figure 3: Basic skills and understanding 
The basic skills that employers deemed very important were computer literacy skills $(n=11$; $92 \%)$, the ability to find and access information $(\mathrm{n}=11 ; 92 \%)$ and written communication skills $(\mathrm{n}=11 ; 92 \%)$. Knowledge of the organisation $(\mathrm{n}=8 ; 67 \%)$ was moderately important, as was the skill for oral presentations $(\mathrm{n}=6 ; 50 \%)$ (Figure 4$)$.

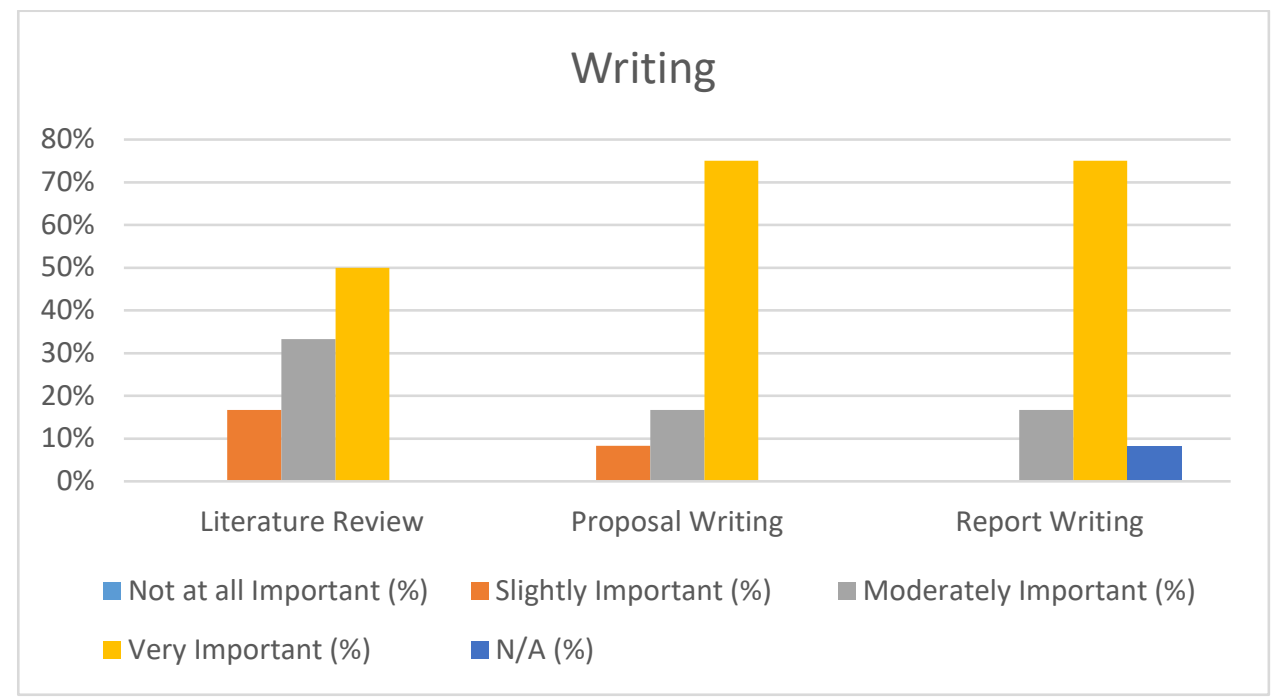

Figure 4: Writing skills

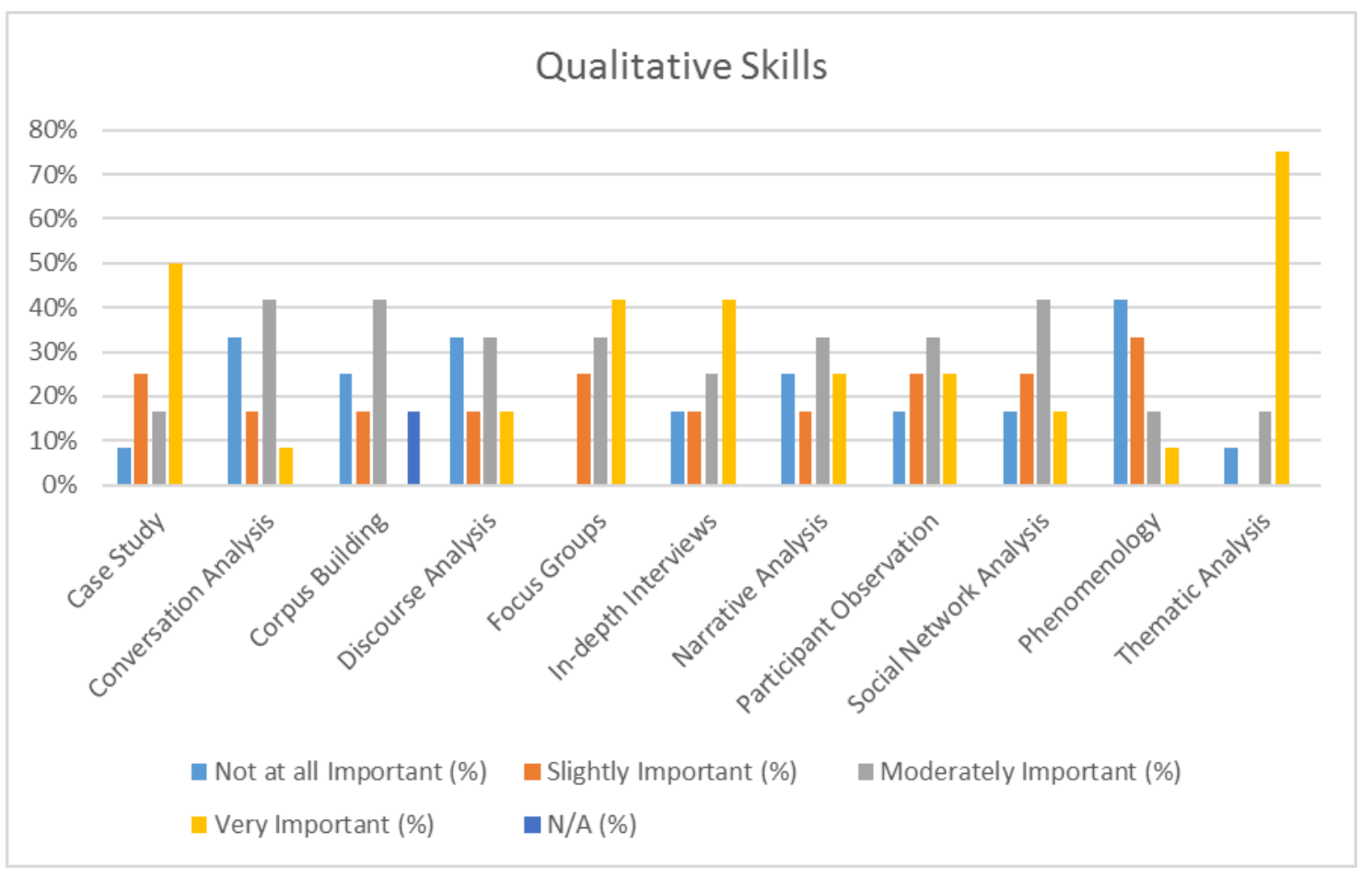

Figure 5: Qualitative skills 
The hard skills surveyed relate to specific knowledge regarding methods, research processes, analytic techniques and critical thinking frameworks embedded within specific methods. In this domain, writing skills and knowledge of quantitative and qualitative techniques were surveyed. Proposal and report writing skills were strongly emphasised and deemed very important with a response of 75 per cent $(n=9)$. Although deemed important, literature review $(n=6 ; 50 \%)$ demonstrated less emphasis than proposal and report writing (Figure 5).

In regard to qualitative skills (Figure 6$)$, thematic analysis $(n=9 ; 75 \%)$ and case study $(n=6 ; 50 \%)$ were deemed the most important skills, followed by in-depth interviews $(42 \% ; n=5)$ and focus groups $(\mathrm{n}=5 ; 42 \%)$. The academic skills of corpus building, social networking analysis and conversation analysis were not regarded as important.

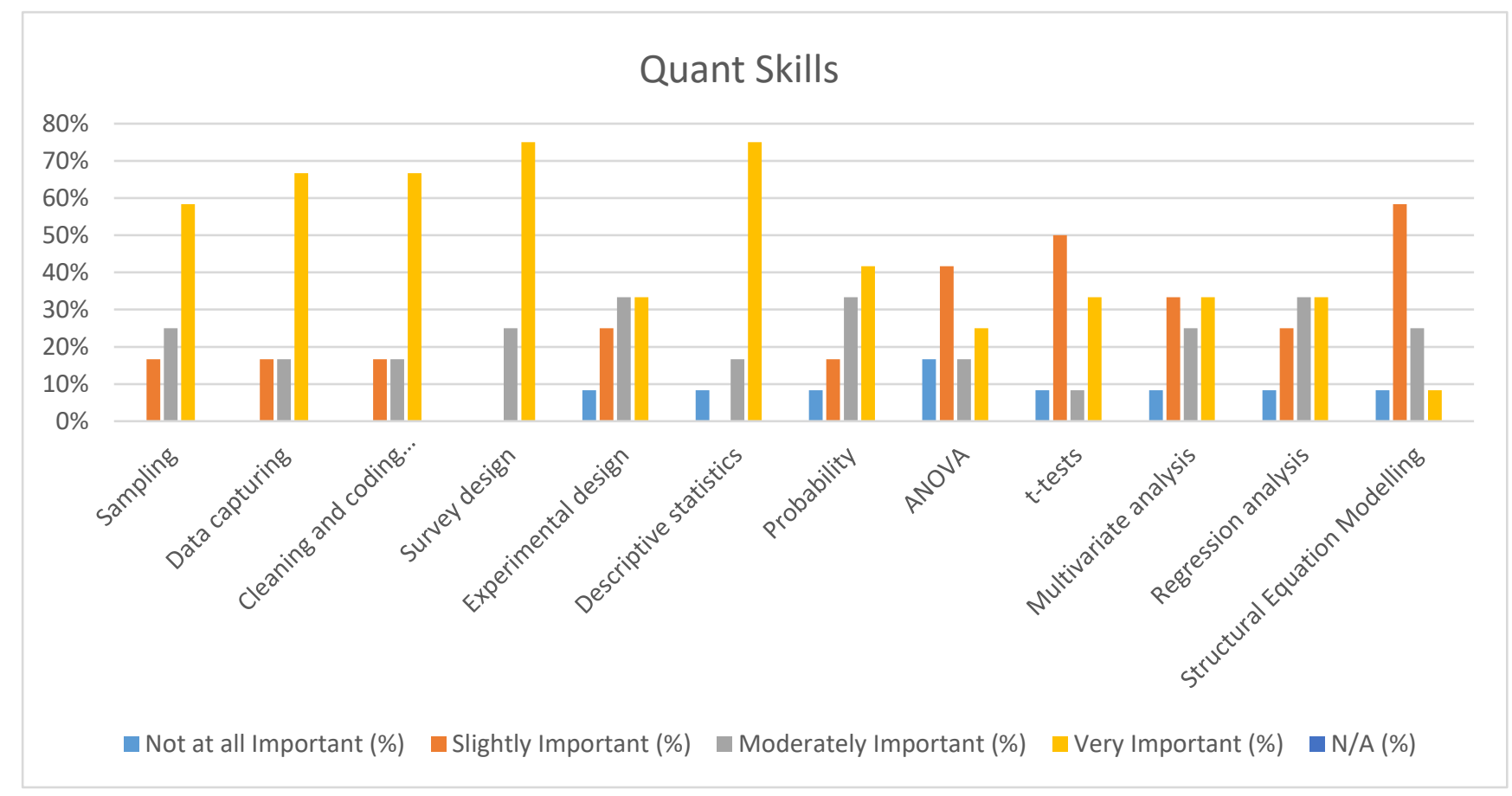

Figure 6: Quantitative skills

In regard to quantitative skills, 75 per cent $(n=9)$ of respondents indicated the ability to perform survey design and descriptive statistics as very important skills. Skills relating to data capturing and cleaning and coding were also reported as very important $(n=8 ; 67 \%)$ (Figure 7$)$.

Although not as important as the abovementioned skills, sampling was reported at 58 per cent, with seven $(n=7)$ respondents stating that it is a very important skill. The advanced qualitative skills involving the academic skills of structural equation modelling $(\mathrm{n}=7 ; 58 \%)$, $\mathrm{t}$ tests $(n=6 ; 50 \%)$, ANOVA $(n=5 ; 42 \%)$ and multivariate analysis $(n=4 ; 33 \%)$ were deemed slightly important. 


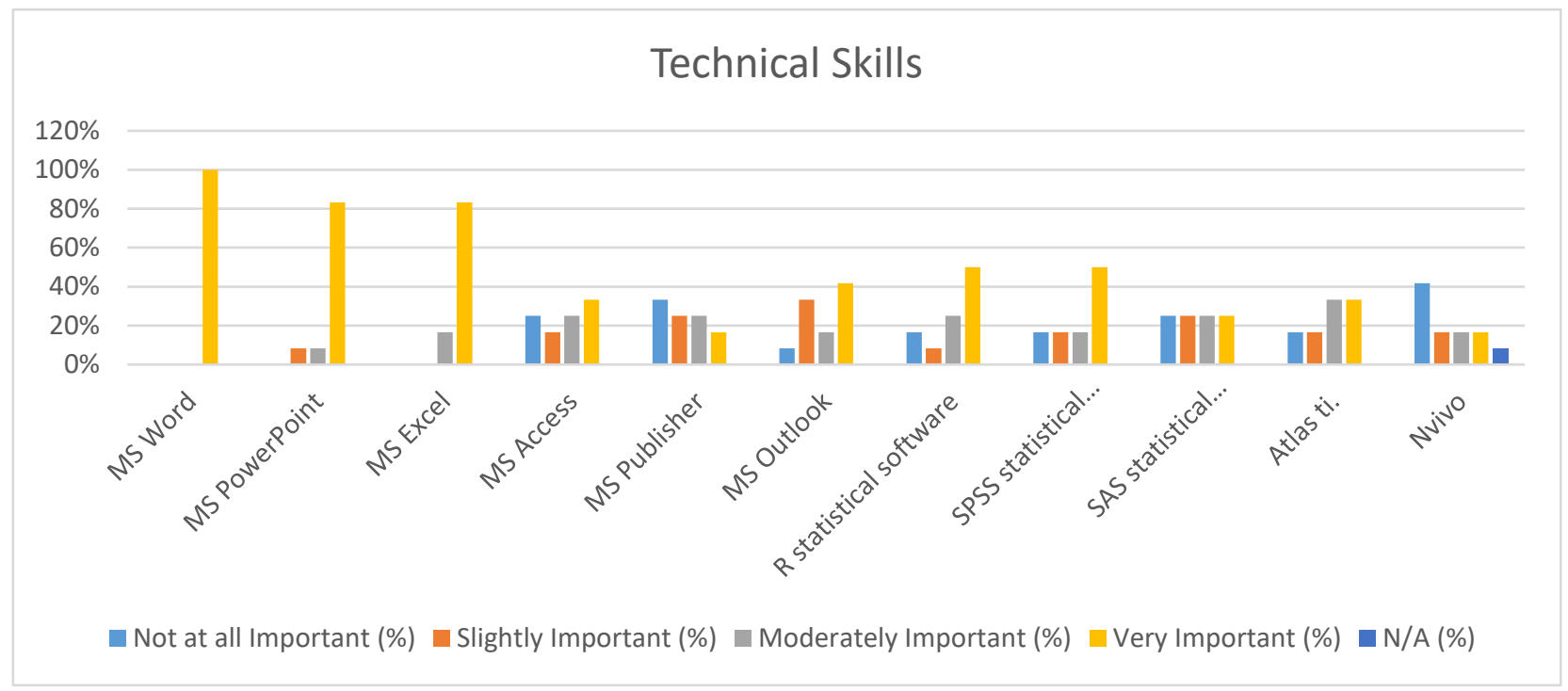

Figure 7: Technical skills

In regard to technical skills, all respondents considered familiarity with MS Word a very important skill (Figure 8). Familiarity with other MS packages such as PowerPoint and Excel was important $(\mathrm{n}=10 ; 83 \%)$, whereas knowledge of advanced programmes such as MS Publisher $(n=4 ; 33 \%)$ and Nvivo $(n=5 ; 42 \%)$ was not considered important.

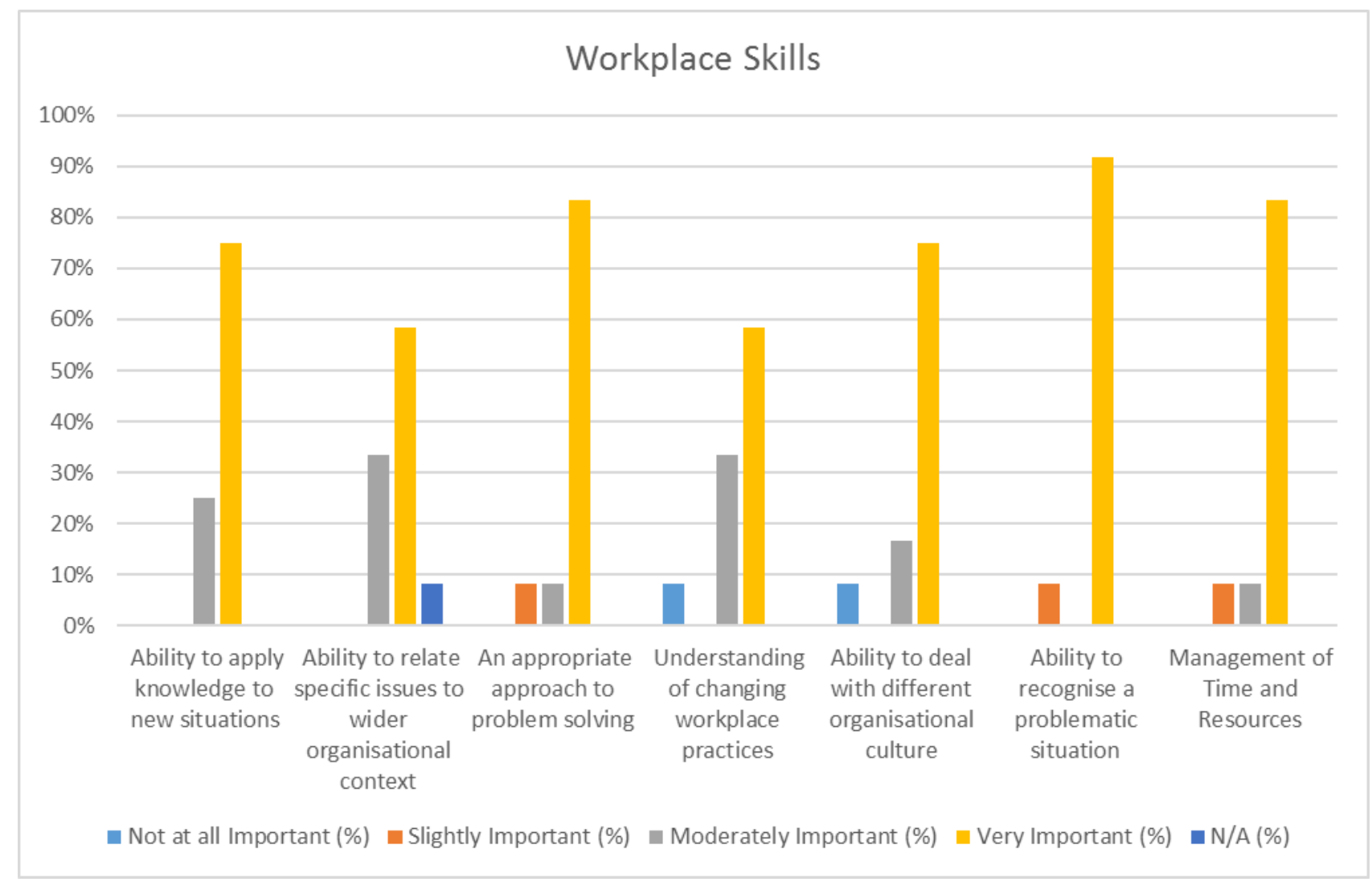

Figure 8: Workplace skills 
Workplace skills such as the ability to recognise a problematic situation $(n=11 ; 92 \%)$, problem solving $(n=10 ; 83 \%)$ and management of time and resources $(n=10 ; 83 \%)$ were considered very important. Less important yet still noteworthy were ability to apply new knowledge to new situations $(n=9 ; 75 \%)$, to deal with different organisational cultures $(n=9 ; 75 \%)$, to understand changing workplace practices $(n=7 ; 58 \%)$ and to relate specific issues to the wider organisational context $(\mathrm{n}=7 ; 58 \%)$ (Figure 9).

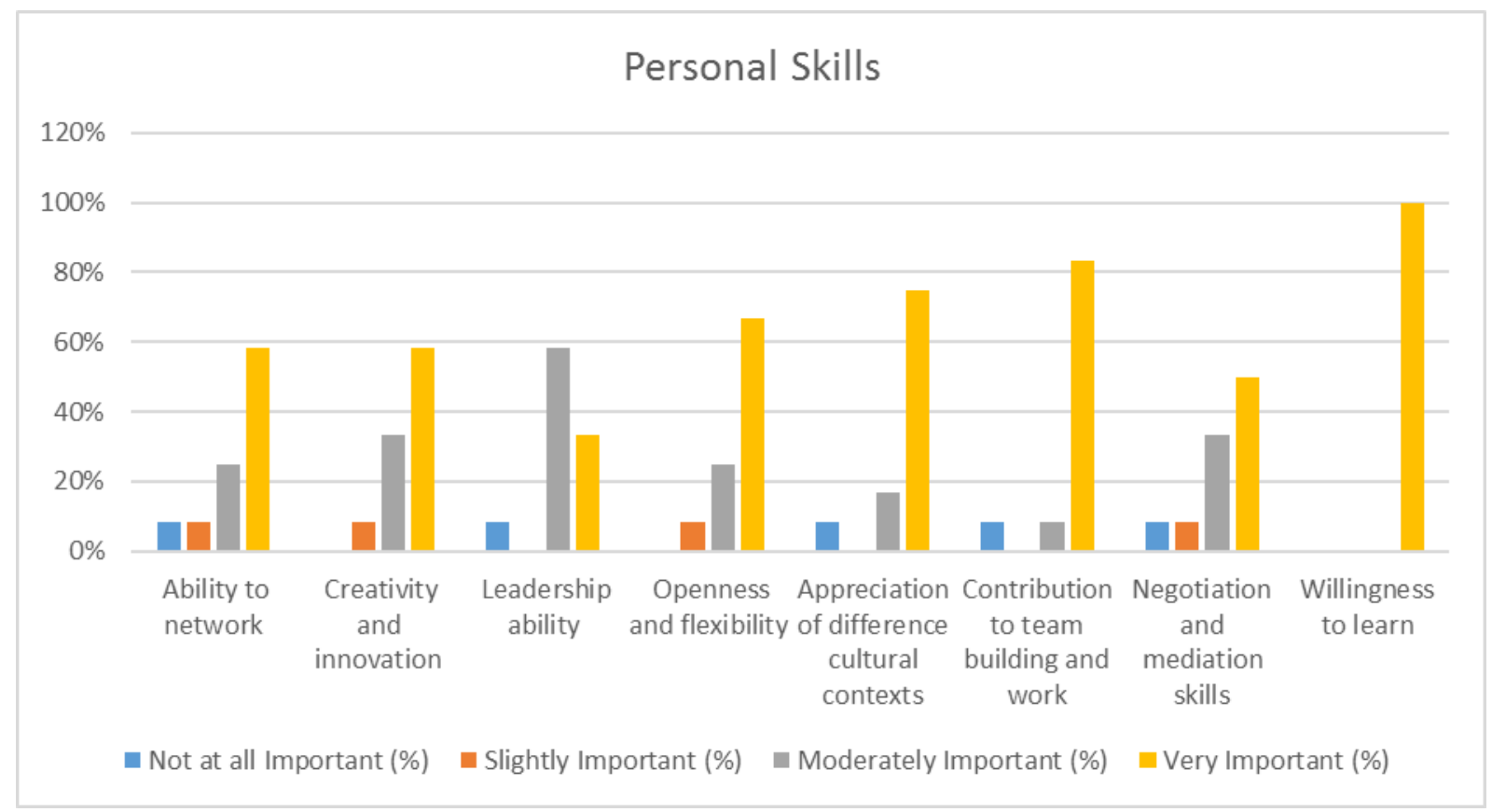

Figure 9: Personal skills

In regard to personal skills, all the employers considered willingness to learn a very important personal skill $(\mathrm{n}=12 ; 100 \%)$. Contribution to team building and work $(\mathrm{n}=10 ; 83 \%)$, followed by appreciation of different cultural contexts $(n=9 ; 75 \%)$, openness and flexibility $(n=8 ; 67 \%)$, creativity and innovation $(n=7 ; 58 \%)$ and the ability to network $(n=7 ; 58 \%)$ were also very important to employers (Figure 9).

\section{DISCUSSION}

The aim of this survey was to determine the perceptions of employers regarding the skills that they deemed important for Research Psychology graduates to become employable in the field of research. The data focused on employers who work closely with employed graduates in research focused fields. A large majority of the respondents (73\%) were located in the Gauteng regions. Most of the respondents worked in an academic institution (27\%) and market research related industries (23\%). Forty-one per cent of respondents reported that they held research 
positions in the organisations and 18 per cent were the head of research unit within their organisations.

The type of qualification and the institution attended influenced employers' beliefs on the quality of educational output and the performance of the graduate (Cai 2012). The above findings by Cai (2012) illustrate the intersection of employability and graduateness. Employers expect HEIs to prepare students for employment after graduation, thus connecting the credibility of the qualification to the credibility of the institution.

According to Stasz (2001), although generic skills or transferable skills are broadly transferable across work settings, they can assume a different meaning in different work contexts. The basic skills surveyed in this study are seen as attributes since such skills are required in graduates regardless of the work setting that they enter.

Within the basic skills domain, both oral and written communication skills were overall the most important soft skills required in graduates. Written communication was very important to 92 per cent of the employers, and this linked well with the importance that employers placed on proposal and report writing, which are both technical skills. The MARC programme allocates 50 hours a year to proposal development and writing, whereas report writing is assigned 6 hours in the year. This may imply that skills such as report writing are assumed to be developed and acquired during the programme without explicitly allocating time to the development of such skills.

Employers deemed oral communication important but proficiency in English was deemed very important by 83 per cent of respondents. English is not South Africa's most spoken language, and it is not the native language of the majority of South Africans. However, English is a universal language and is largely spoken in places of work in order to remove language barriers. With the majority of South Africans not being native to English, being able to communicate in English is an often overlooked soft skill that is expected when entering university and the labour market.

Another soft skill that employers deemed important was computer literacy (92\%). Computer literacy means having the most basic knowledge and skills to operate software products and applications. Technology has made it nearly impossible for workplaces to function without computers; computers not only improve communication but also improve efficiency, use less paper and contribute to the workplace culture. Thus, computer literacy is an essential skill for a graduate. The MARC programme currently commits 7 per cent of the overall on-campus training to computer skills training.

These skills are increasingly viewed as core skills within the knowledge and information economy in which most employers operate. For instance, computer literacy is a fundamental 
requirement of most employers, particularly within white-collar settings such as research-related fields. Furthermore, the emphasis on accessing, evaluating and synthesising large amounts of information is critical in an age where there is a proliferation of information available on the internet in both public and private databases. Graduates are, therefore, expected to be able to navigate the myriad of information sources to find the most relevant information as efficiently as possible.

Although a technical skill, 83 per cent of the employers emphasised familiarity with computer software applications such as MS Excel. The MARC programme aligns with this and allocates 15.5 hours in the year on such training. However, other software packages such as MS Word and PowerPoint are not explicitly included in the programme. All the employers $(100 \%)$ deemed MS Word very important and considered MS PowerPoint as important as Excel. In the context of South Africa where computer literacy rates are generally low, the assumption that students have already gained this knowledge during training should be questioned. In addition, consideration needs to be given to training on packages other than Excel within curricula.

The applied skills focused specifically on the research-specific skills that employers of Research Psychology graduates would require. The survey combined these hard skills with academic skills. Stasz (2001) identifies hard skills as the specific skills that the graduate needs to possess and the specific knowledge of certain tools and processes that is needed within the work place. This survey combined applied skills with academic skills since both categories associate with a subject area learnt in school (Stasz 2001). The inclusion of academic skills could assist in identifying if subject areas learnt in the classroom can be transferred to the workplace.

Qualitative analysis programmes such as Nvivo and Atlas.ti are largely used to conduct thematic analysis. However, the results show that employers do not consider the ability of graduates to use these programmes as important. This is probably due to the fact that these programmes are licenced and obtaining them would incur quite an expense for the company. On the contrary, HEIs are able to make these programmes available to their students through funding. Additionally, thematic analysis can also be done on MS Excel, which explains the importance that employers placed on MS Excel as not only a writing tool but also an analysis tool when needed.

The importance employers placed on quantitative skills, specifically descriptive statistics, data capturing, and cleaning and coding highly correlates with the emphasis they placed on MS Excel. The software MS Excel is widely and routinely used by organisations across sectors, whereas the specialised statistics software that graduates are trained on is costlier and, therefore, 
not as widely accessible.

Training programmes for MA Research Psychology emphasise training in qualitative and quantitative research methodology with the intention that students can apply this knowledge to their own studies and within the labour market. While both employers and the training programmes agree on the importance of methodological training, the results showed gaps in the focus of the MARC programme when compared with employer expectations.

Employers emphasised the soft skills that are important in the functioning and harmonisation of individuals and teams in the workplace. In order to keep the workplace functioning and in harmony, 92 per cent of the employers placed importance on the ability to recognise problematic situations. The ability to identify the problem and to formulate an appropriate approach to solving the problem was seen as important by 83 per cent of employers. The importance placed on these skills demonstrates employers' need for innovative and solution-driven students to meet the growing demands of the market.

Within the context of this study, workplace skills are referred to as the soft skills that employers deem important in ensuring the harmonised functioning of individuals within teams and in the larger organisational context. Workplace skills also hold a measure of overlap with the more abstract transferrable skills such as problem identification and problem solving and demonstrate whether or not individuals are able to relate to their role within the procedures and practices of the organisation. The workplace has evolved through technological advances that have created a space in which efficiency is key, thus introducing the pressures of keeping up and conserving resources. Management of time and resources was considered important by 83 per cent of employers in industries where monetary capital is solely reliant on clients. The management of resources is of outmost importance in such organisations because a lack of this skill would mean a loss for the organisation.

Interpersonal and interactive skills are soft skills that are gaining prominence in graduateness literature. Stasz (2001) views work-related attitudes or soft skills as the way in which an individual's character or personality is shown within the workplace. The ability to relate to colleagues and clients plays a crucial role in ensuring overall organisational and individual success. These skills are particularly important within multicultural contexts such as occur in South Africa where relating to others across linguistic and cultural boundaries are real experiences for most South African employees.

South Africa is a multicultural and multilingual country in which different individuals come together to create a workplace. For the workplace to be successful, employers need graduates who are adaptable and have the ability to deal with different organisational cultures (75\%), graduates who can deal with the changes of work practices $(58 \%)$ and graduates who 
have an appreciation of different cultural contexts (75\%). These skills indicate the adaptability of the graduate; an adaptable employee is able to work independently and in a team. The importance of adaptability is demonstrated by 83 per cent of employers placing importance on contribution to team building and work as an interpersonal skill. These skills demonstrate individual abilities that meet the performance expectations of the workplace and contribute to the overall adaptability of the organisation in the labour market.

Willingness to learn was a major personal skill that 100 per cent of employers deemed important. There has been an increasing demand for skilled employees in the workplace, resulting in employers sending more employees into training. These training programmes ensure that employees receive good information and can thus make a significant impact on the organisation at a later stage.

\section{CONCLUSION}

From the results above, it is apparent that employers within the field of Research Psychology place great emphasis on the soft skills. These findings are in line with the work of other authors such as Winberg (2006) and Robles (2012) who highlight that soft skills such as the ability to interact competently with colleagues, the ability to interact across racial and cultural differences and the willingness and ability to learn new skills are increasingly seen as key skills within knowledge-driven industries (Bridgstock 2009). Given the dynamic nature of the economy where seemingly gestalt shifts occur within industries in terms of technology, trends and ideology, the adaptability inherent in the soft skills highlighted as crucial would yield an employee who would continue to contribute to the organisation under changing conditions. While technical skills are considered part of the decision to employ a graduate, the need for specific technical skills and competence in these skills varies slightly among employers. The abilities highlighted as technical skills are closely tied to the available technology and accepted research practices and procedures, and these may not be relevant as the organisational context shifts. The implications of the above findings for institutions is that a more considered, scaffolded and structured focus on developing soft skills is required within the training curricula for Research Psychology students. We agree with Stasz (2001), Bridgstock (2009) and Archer and Chetty (2013) that there has been an increasing shift in universities where employability has become a measure for graduate employment and the university's ability to produce qualifications relevant to the labour market.

University programmes tend to focus on disseminating content knowledge and developing technical skills. This focus appears to be the case with the Unisa Research Psychology Master's programme in which a large proportion of the training time is dedicated to exposing students to 
core theoretical models and to developing technical research skills. This programme places less emphasis on the structured development of soft skills, relying instead on work-integrated learning practices to develop learning opportunities. Universities need to develop soft skills in programmes in order to produce a graduate who is able to adapt ever changing labour market. The Unisa Research Psychology Master's programme offers a case in which soft skills have been implemented as part of the programme by including facilitated work placements. The purpose of the work placement in the Unisa Research Psychology Master programme is to equip students with context related knowledge and skills to prepare them for when they graduate. The researchers in this survey argue that a more explicit focus on soft skill development could further enhance the work exposure of students as they are directed and facilitated through the process of developing the key soft skills.

\section{LIMITATIONS AND RECOMMENDATIONS}

One of the primary limitations of this study is the focus on initial graduate destinations as an indicator of employability. While this approach is widely used in studies regarding graduate employability, critics of the approach assert that the career trajectories of graduates remain largely unexamined. Within the context of rapidly changing business and employment markets, authors such as Bridgstock (2009) place emphasis on a graduate's ability to self-manage career building to ensure long-term employability. The notion of linear career progression within an organisation no longer adequately depicts the world of work, and the modern graduate and institution need to move beyond the narrow definitions of employability (Bridgstock 2009). In view of the argument made by Bridgstock (2009), longitudinal studies of graduate employability should be considered to ascertain the career progression and the evolution of graduates within and across various industries.

A further limitation of this study is the relatively small response set that prescribes the generalisability of the findings beyond the response sample. While the findings provide valuable insight into the expectations of employers, further studies are required to determine the destinations of graduates from Research Psychology programmes. This in turn will assist with targeting and profiling the needs of employers within the various sectors.

Future studies in this field could focus on the initial and long-term employment experiences of graduates from Research Psychology programmes. This may provide further insight into the job-seeking strategies employed by graduates from these programmes.

\section{REFERENCES}

Archer, Elizabeth and Yuraisha Chetty. 2013. Graduate employability: Conceptualisation and findings 
from the University of South Africa. Progressio 35(1): 134-165.

Bridgstock, Ruth. 2009. The graduate attributes we've overlooked: Enhancing graduate employability through career management skills. Higher Education Research and Development 28(1): 31-44. doi:10.1080/07294360802444347.

Cai, Yuzhuo. 2013. Graduate employability: A conceptual framework for understanding employers' perceptions. Higher Education. doi:10.1007/s10734-012-9556-x.

Cheong, Kee Cheok, Christopher Hill, Rozilini Fernandez-Chung and Yin Ching Leong. 2016. Employing the "unemployable": Employer perceptions of Malaysian graduates. Studies in Higher Education 41(12): 2253-70. doi:10.1080/03075079.2015.1034260.

Coetzee, M. and D. Schreuder. 2011. The relation between career anchors, emotional intelligence and employability satisfaction among workers in the service industry. Southern African Business Review 15(3): 76-97. doi:10.4102/sajhrm.v8i1.279.

Collet, Chris, Damian Hine and Karen du Plessis. 2015. Employability skills: Perspectives from a knowledge-intensive industry. Education and Training 57(5). doi:10.1108/ET-07-2014-0076.

Council of Higher Education. 2011. Work-integrated learning: Good practice guide. HE Monitor.

Derman, Lauren. 2002. "Employment trends in research psychology in South Africa: 1976-1998."

Fourie, E., A. Fynn and E. Long. 2014. "Self-evaluation report: Master's Programme in Research Consultation (Marc) in Psychology." doi:10.2767/39856.

Griesel, Hanlie and Ben Parker. 2009. Graduate attributes: A baseline study on South African graduates from the perspective of employers in graduate attributes.

Health Professions Council of South Africa. n.d. "Professional Board for Psychology list of accredited universities in South Africa." https:/www.hpcsa.co.za/Uploads/editor/UserFiles/downloads/ education_training/psych/psychology_accredited_universities_feb.pdf

Knight, Peter T. and Mantz Yorke. 2003. Employability and good learning in higher education. Teaching in Higher Education 8(1): 3-16. doi:10.1080/1356251032000052294.

Kruss, Glenda. 2004. "Employment and Employability: Expectations of Higher Education Responsiveness in South Africa." Journal of Education Policy. doi:10.1080/0268093042000300454.

Laher, Sumaya. 2005. The Status of Research Psychology in South Africa. https://www.researchgate. net/publication/263661804.

Long, Errolyn and Angelo Fynn. 2018. Postgraduate student experiences of workplace learning for a professional psychology qualification in the South African context." Industry and Higher Education 32(5): 341-50. doi:10.1177/0950422218774701.

Moleke, Percy. 2003. Employment experiences of graduates. http://www.hsrc.ac.za/en/researchdata/view/1388

Potgieter, Ingrid and Melinde Coetzee. 2013. Employability attributes and personality preferences of postgraduate business management students." SA Journal of Industrial Psychology doi:10.4102/sajip.v39i1.1064.

Rascher, Candice. 2016. After the degree: Research psychology in the "real world". University of the Witwatersrand.

Robles, Marcel M. 2012. Executive perceptions of the top 10 soft skills needed in today's workplace. Business Communication Quarterly. doi:10.1177/1080569912460400.

Stasz, C. 2001. Assessing skills for work: Two perspectives. Oxford Economic Papers. doi:10.1093/oep/53.3.385.

The National Council for the Social Studies. n.d. Appendix I Essential Social Studies Skills and Strategies. https://www.mcpsmt.org/cms/lib/MT01001940/Centricity/Domain/825/APPENDIX I Essential Social Studies Skills and Strategies.pdf.

Winberg, Christine. 2006. Undisciplining knowledge production: Development driven higher education 
in South Africa. Higher Education. doi:10.1007/s10734-004-6378-5.

Yorke, Mantz. 2005. Employability in higher education: What it is - What it is not. Learning \& Employability 1: 24. doi:10.1002/ir.162.

Yorke, Mantz. 2006. Employability in higher education: What it is - What it is not." 1. Learning \& Employability. York, United Kingdom. 